\title{
La falta injustificada o sin aviso previo del trabajador que perturba gravemente la marcha de la empresa*
}

\author{
Pedro Irureta Uriarte**
}

\begin{abstract}
RESUMEN
En el contexto de la extinción disciplinaria del contrato de trabajo, el legislador chileno ha regulado un tipo especial de abandono consistente en faltar sin aviso previo o injustificadamente a las labores, siempre que el trabajador tuviese a su cargo una actividad, faena o máquina relevante dentro de la empresa. Si ese abandono o inasistencia provoca una perturbación grave para el empleador, entonces el Código del Trabajo entiende que este se encuentra facultado para extinguir el contrato. Se trata de una figura de falta o abandono transitorio, que requiere de efectos perjudiciales graves, y que está construida para aquel infractor que no tiene reemplazante.
\end{abstract}

Abandono - inasistencia - término del contrato

\section{The employee's unjustified or without notice absence that seriously disturbs the progress of the company}

\begin{abstract}
In the context of disciplinary termination of the employment contract, the Chilean legislature has regulated a special kind of abandonment, which consists in the employee's unjustified or without notice absence to work, in case he or she is in charge of an activity, task or relevant machine within the company. If the absence seriously disturbs or affects the employer, then the Labor Code understands that the employer is entitled to terminate the contract. It is a figure of misconduct or temporary abandonment that requires serious damage effects, and provoked by an offender who has no replacement.
\end{abstract}

$$
\text { Abandonment - absence - termination of contract }
$$

* Abreviaturas: AFDO (Anuario de la Facultad de Derecho de Ourense); AL (Actualidad Laboral); CT (Código del Trabajo); RD (Revista de Derecho Valparaíso); RDJ (Revista de Derecho y Jurisprudencia y Gaceta de los Tribunales); RFM (Revista Fallos del Mes).

** Abogado y Licenciado en Derecho, Pontificia Universidad Católica de Chile. Doctor en Derecho, Universidad Complutense de Madrid. Profesor titular de Derecho del Trabajo de la Universidad Alberto Hurtado. Correo electrónico: piruret@uahurtado.cl. El presente trabajo se inscribe dentro del proyecto de investigación Fondecyt $\mathrm{N}^{\circ} 1140993$, denominado "La configuración de los elementos centrales de las causas disciplinarias de extinción del contrato de trabajo", ejecutado por el autor en la Universidad Alberto Hurtado en calidad de investigador responsable.

Artículo recibido el 20 de enero de 2015 y aceptado para su publicación el 21 de enero de 2016. 


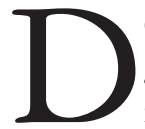

entro de la causal extintiva del artículo $160 \mathrm{~N}^{\circ} 3 \mathrm{CT}$, referida a supuestos genéricos de inasistencia, el legislador nacional ha incluido supuestos específicos de abandono. El abandono que se reprocha es, en principio, aquel que se vincula con el puesto de trabajo, de destino o de funciones, y que impide que el trabajador realice la prestación debida. De esta manera, siguiendo al Código, el contrato de trabajo se extingue por la falta injustificada, o sin aviso previo de parte del trabajador que tuviere a su cargo una actividad, faena o máquina cuyo abandono o paralización signifique una perturbación grave en la marcha de la obra.

Como resulta evidente, se trata de una causal más rigurosa si se le compara con los demás casos de inasistencia que regula el Código. En este supuesto en particular, a la normativa legal parece bastarle una ausencia transitoria (o de menos de dos días) que no se encuentre justificada o bien que no haya sido precedida de un aviso previo ${ }^{1}$. Desde luego, estos supuestos no se refieren a actos constitutivos de incumplimiento en que el trabajador se ausenta voluntariamente con la intención de poner término al contrato, como si se tratara de una especie de renuncia tácita. Tampoco puede incluir hipótesis de ausencia justificada. Por el contrario, lo que subyace en esta causal es un incumplimiento contractual (consistente en la falta de presencia una vez que se ha iniciado la jornada, así como en abandonos transitorios o en ausencias aisladas) que faculta a que el empleador pueda poner término al contrato por causa disciplinaria del trabajador. En esta lógica se sitúan, como ya se ha dicho, el abandono de destino, el abandono de puesto o el abandono de funciones ${ }^{2}$.

El destinatario de la norma es un trabajador con un nivel determinado de responsabilidad sobre la actividad, faena o máquina. Desde esta perspectiva, no podría ser autor de la infracción aquel trabajador que, sin ser el responsable de la actividad, faena o máquina, se comporta como un mero instigador o como simple colaborador en la producción de la falta, ya que el nivel de especialización y responsabilidad que se le exige al eventual autor del ilícito obliga a desterrar alternativas en que falte ese elemento. Similares conclusiones podrían extraerse respecto de aquel trabajador que participa en el encubrimiento de la infracción ("es decir, simular la presencia de otro trabajador, fichando o firmando por aquel" ${ }^{3}$ ). Ciertamente, dicha conducta puede ser objeto de reproche por medio de la causal vinculada al incumplimiento grave de las obligaciones (art. $160 \mathrm{~N}^{\circ} 7 \mathrm{CT}$ ); pero la norma del artículo $160 \mathrm{~N}^{\circ} 3 \mathrm{CT}$ a la que haremos referencia no está pensada para un trabajador que participa en el mero encubrimiento.

De igual modo, el diseño de la causal parte del supuesto que el trabajador responsable o debidamente cualificado se ha ausentado de forma injustificada de sus tareas provocando una determinada consecuencia perturbadora, cuestión que impide englobar dentro de la falta hipotéticos casos de tentativa. En efecto, la parte final del artículo 160

${ }^{1}$ Cfr. Macchiavello, G., Derecho del Trabajo T. I, Fondo de Cultura Económica, Santiago, 1986, p. 520.

${ }^{2}$ Cfr., Montoya, A., Derecho del Trabajo, Tecnos, 29a edición, Madrid, 2008, p. 462.

${ }^{3}$ Vid. Rodríguez, E., "Las faltas de asistencia o puntualidad al trabajo como infracción disciplinaria: su regulación convencional”, AFDO No 1, 2006, p. 439. 
$\mathrm{N}^{\circ} 3 \mathrm{CT}$ es perentoria en el sentido que el abandono o la paralización debe traer como consecuencia una perturbación grave en la marcha de la obra. Esa referencia normativa pone el acento en el resultado; por tanto, una teórica tentativa de dejar de asistir al empleo, sin las consecuencias a que se refiere el artículo $160 \mathrm{~N}^{\circ} 3 \mathrm{CT}$, hacen imposible que se configure la infracción. Como resulta evidente, en la tentativa no hay resultado de perturbación.

Tal como se señaló con anterioridad, los supuestos de abandonos transitorios y aislados no adquieren en términos generales la gravedad suficiente para justificar la extinción del contrato. Tanto es así, que la parte primera del artículo $160 \mathrm{~N}^{\circ} 3$ CT tuvo que establecer una reiteración mínima (de dos días seguidos o de tres días en el mes) que permitiera extinguir justificadamente el vínculo. No obstante, la situación es distinta si la inasistencia recae en un trabajador que tiene a su cargo un servicio genéricamente relevante dentro de la empresa y cuya ausencia termina provocando consecuencias perturbadoras para la organización.

Bajo la vigencia del Código de 1931, esta causal se encontraba incorporada en los supuestos de abandono. De esta manera, se justificaba la extinción del contrato en todas aquellas hipótesis en que el trabajador abandonase el puesto de trabajo sin causa justificada. Ello permitió que, en los primeros años de aplicación de la normativa laboral, esta norma se utilizara para sancionar, por ejemplo, el abandono de las labores por parte de determinados trabajadores a objeto de participar en una huelga ilegal ${ }^{4}$.

Con la Ley $\mathrm{N}^{\circ} 16.455$ (de 1966), la figura extintiva fue refundida con la causal genérica de inasistencias y se presentó con una estructura gramatical prácticamente igual a la que existe en el actual artículo 160 No 3 CT; salvo por dos diferencias. La primera de ellas se refiere a una cuestión meramente formal: la mencionada Ley $\mathrm{N}^{\mathrm{o}} 16.455$ agregaba, después de la expresión "sin aviso previo", las voces "al trabajo", de forma tal que no existiera duda de que el abandono o paralización se encontraba vinculado a las actividades desarrolladas en el "trabajo" y no a otras que eventualmente pudiesen realizarse fuera del contexto laboral. La segunda diferencia es más relevante toda vez que a partir del Decreto Ley $\mathrm{N}^{\circ} 2.200$ (de 1978), el legislador incorporó la idea de que la perturbación debía ser grave (expresión que no se contenía en el texto de la Ley $\left.\mathrm{N}^{0} 16.455\right)^{5}$. Este agregado, que ha permanecido hasta hoy, no es casual, pues reafirma la tesis de que la infracción debe tener una consecuencia relevante en la marcha de la empresa. La señal que manda el legislador en este punto es que el ilícito se configura siempre y cuando el resultado deje en evidencia una perturbación de tal nivel y entidad que ella es merecedora de la máxima sanción disciplinaria.

\footnotetext{
${ }^{4}$ Cfr. sentencia de la Corte Suprema de 12 de enero de 1934. RDJ T. XXXI, 1934, sección primera, p. 223.

${ }^{5}$ Artículo $14 \mathrm{~N}^{\circ} 3$ del decreto ley $\mathrm{N}^{\circ} 2.200$, de 1978.
} 


\section{LA NATURALEZA DE LA FALTA}

La parte segunda del artículo $160 \mathrm{~N}^{\circ} 3$ CT comienza describiendo la infracción como una falta injustificada o sin aviso previo. Esa es la conducta prohibida que pesa sobre el trabajador. Con todo, la expresión falta injustificada o sin aviso previo debe ser vista como una clara infracción a los deberes del cargo que pesan sobre el trabajador y que engloban tanto la ausencia física del sitio así como el incumplimiento absoluto y total de las tareas contractualmente asumidas Dicho de otra manera, la falta se refiere por una parte a la ausencia del trabajador del lugar en que debe estar; y por otra, también comprende la realización de una conducta u omisión consistente en no asumir las tareas que le corresponden en la máquina, actividad o faena, aun cuando se encuentre presente en el centro de trabajo ${ }^{6}$.

El hecho objetivo de la inasistencia "injustificada" o "sin aviso previo" obliga a dejar fuera del núcleo definitorio de la infracción aquellos supuestos en que el trabajador hace abandono de la actividad, durante la jornada de trabajo, autorizado y justificado por su jefe directo de forma expresa o tácita ${ }^{7}$. También deberían excluirse los abandonos transitorios fundados en supuestos de fuerza mayor o caso fortuito ${ }^{8}$, o aquellos que no requieren de autorización especial del empleador ${ }^{9}$. Incluso la mera impuntualidad no parece reunir los ribetes de gravedad a los cuales se enfoca la causal (sin perjuicio de los alcances que tenga dicha infracción de acuerdo con el núcleo definitorio del artículo $160 \mathrm{~N}^{\circ} 7 \mathrm{CT}$ : incumplimiento grave de las obligaciones $)^{10}$. A mayor abundamiento, no formarían parte del núcleo central de esta causal las faltas dolosas o imprudentes que afectan la seguridad o funcionamiento de las personas o de la empresa, o bien el perjuicio material sobre determinados bienes que el trabajador tiene a su cargo, ya que ello sería más propio de las figuras sancionadas en el artículo $160 \mathrm{~N}^{\circ} 5$ y 6 CT.

\footnotetext{
${ }^{6}$ Cfr. la distinción de ambas figuras en Arias, Á., Absentismo laboral, Civitas/Thomson Reuters, primera edición, Madrid, 2013, p. 35.

${ }^{7}$ Cfr., sentencia de la Corte Suprema de 4 de abril de 1990, RDJ T. LXXXVII, sección tercera, 1990, p. 28. Vid. también sentencia de la Corte Suprema de 7 de enero de 1982, RDJ T. L XXIX, sección tercera, 1982 , p. 1, en que el trabajador avisó de la ausencia a su jefe directo, "con anuncio de petición de permiso con cargo a feriado disponible, y sin que dicho jefe manifestara oposición. La negativa posterior al permiso solicitado no parece justa (...)".

${ }^{8}$ Vid. sentencia de la Corte Suprema de 17 de mayo de 1991, RDJ T. LXXXVIII, sección tercera, 1991, p. 48 (considerando cuarto): “(...) la causal se produce si falta injustificadamente, o si falta sin aviso previo, aunque sea justificadamente, salvo, como es obvio, el caso de fuerza mayor, porque nadie está obligado a lo imposible, de manera que si a ese trabajador le da verbi gratia, un infarto cardiaco, o si es víctima de un asalto, la causal no opera; pero esto es así con arreglo a los principios generales del derecho, que no precisan estar escritos".

${ }^{9}$ Vid., en esta línea, sentencia de la Corte Suprema de 8 de mayo de 1980, RDJ T.LXXVII, sección tercera, 1980 , p. 20. En este caso, un trabajador se había retirado del lugar de trabajo para almorzar en su domicilio. Según la Corte, aquí no existe abandono de funciones toda vez que "de los términos del contrato de trabajo no aparece en forma expresa la obligación de permanecer en el casino de la empresa a la hora de colación".

${ }^{10}$ Cfr. por todos Altes, J. A., Blasco, Á., y Nores, L. E., El despido objetivo, Tirant lo Blanch, Valencia, 2010 , p. 43.
} 
La redacción de la causal parece no exigir un dolo o culpa especial en la ejecución de la conducta prohibida. Solo bastaría una actitud voluntaria cuyo resultado sea la provocación de una grave perturbación en las actividades, faenas o máquinas de la empresa. Como ya advertían algunos comentaristas de la Ley $\mathrm{N}^{0} 16.455^{11}$, la conjunción "o" es disyuntiva, de forma tal que la falta solo requiere de alguno de estos atributos (injustificada o sin aviso previo) para que el empleador pueda fundadamente poner término al contrato. Por ejemplo, si el trabajador ha avisado previa y oportunamente de su ausencia, aun cuando sea sin motivo justificado, entonces difícilmente podrá configurarse esta específica causal de despido ${ }^{12}$.

La exigencia de justificación de la inasistencia nos reconduce a los criterios generales que la jurisprudencia ha esgrimido respecto de la racionalidad y sensatez de la explicación justificativa ${ }^{13}$. Por ello, cada vez que exista precepto legal, reglamentario o circunstancias de indudable valor que disculpen la inasistencia, no resultaría factible aplicar la causal. Por el contrario, cada vez que no exista razón alguna o bien cuando se aleguen razones inciertas, inadecuadas o insuficientes, no habrá justificación ${ }^{14}$. En cuanto al aviso previo, es factible tener presente que el legislador ha señalado un período temporal para la comunicación (aun cuando sea injustificada): antes de la inasistencia. En este orden de ideas, el aviso posterior solo puede aceptarse en tanto cuando implique una comprobación de la justificación ${ }^{15}$.

\section{EL ABANDONO O PARALIZACIÓN}

La conducta principal que se sanciona en la segunda parte del artículo $160 \mathrm{~N}^{\circ} 3$ CT es la falta o inasistencia injustificada o sin aviso previo por parte del trabajador; y a partir de dicha infracción se produce un efecto: el abandono o la paralización de la actividad, faena o máquina. En el primer caso, se pone el acento en el desamparo en que queda una actividad, faena o máquina de la empresa a raíz de la ausencia. En definitiva, el abandono implica una dejación de ciertos bienes o actividades y ello está

${ }^{11}$ Vid. DAVIS, P.R., Terminación del contrato de trabajo, Editorial Bibliográfica Chilena, Santiago, s/f, p. 57.

${ }^{12}$ Cfr. Macchiavello, T. I, cit., p. 520. Vid. además sentencia de la Corte Suprema de 17 de mayo de 1991, RDJ T. LXXXVIII, sección tercera, 1991, p. 45. Parte de la doctrina nacional que analizó esta norma en la Ley $\mathrm{N}^{\circ} 16.455$ (cfr. Domínguez, M., Manual para la aplicación de la ley $N^{0} 16.455$ y su reglamento sobre inamovilidad en el empleo, Edilex, Santiago, s/f, p. 18), concluía en todo caso que no habría derecho al despido si el trabajador justifica las razones de no haber dado aviso previo.

${ }^{13}$ Cfr. por todas sentencia de la Corte Suprema de 28 de julio de 2010, RFM No 554, 2010, p. 513; y sentencia de la Corte Suprema de 24 de enero de 2006., RDJ T. CIII, sección tercera, 2006, p. 225:

${ }^{14}$ Cfr. Gil, J., "Las faltas repetidas e injustificadas de asistencia o puntualidad al trabajo como causa de extinción de los contratos", AL N ${ }^{\circ}$ 1, 2005, p. 1464.

${ }^{15}$ Vid. en relación a una norma similar, la discusión jurisprudencial que se ha producido sobre este tema en el derecho mexicano, en De Buen, N., Derecho del Trabajo, T. II, Porrúa, 9a edición, México, 1992, p. 97. Vid. También Sagardoy, J. A., El despido laboral y los expedientes de crisis, Ediciones Deusto, Bilbao, 1969, p. 69. 
inserto en la lógica con la que se estructura la causal. Como ya se ha dicho, en el caso particular de esta infracción la dejación no implica necesariamente una separación física absoluta entre el trabajador y el lugar en el que funciona la empresa; por el contrario, una correcta interpretación de la causal supone que el ilícito está vinculado al hecho de dejar de atender los deberes del cargo cuestión que trae como consecuencia el no proseguir con la actividad o con el funcionamiento de las máquinas o faenas. Ese sería el caso, por ejemplo, de un trabajador que decide no reintegrarse a las labores después de terminado el tiempo de colación, permaneciendo en aquellos lugares que la empresa tiene destinado como comedores más allá del período correspondiente. O bien, aquella persona que decide retirarse anticipadamente afectando de ese modo el funcionamiento normal de la empresa.

Nota aparte merecen los casos de impuntualidad. Los atrasos propiamente tales deben ser encuadrados en la hipótesis del artículo 160 N 7 CT (y no en la hipótesis del artículo $160 \mathrm{~N}^{\circ} 3 \mathrm{CT}$ ), toda vez que el Código pone el acento en las faltas e inasistencias. Los atrasos, por el contrario, implican una acción de retraso que deja al descubierto el llegar tarde, cuestión cualitativamente distinta a la no concurrencia. Por lo demás, una firme razón de texto obliga a concluir que el Código al configurar la causal hace referencia a las faltas e inasistencias, y no a las impuntualidades. Incluso, ha sido la propia jurisprudencia la que ha indicado que los atrasos son sancionables en cuanto sean reiterados y graves ${ }^{16}$, cuestión que -al menos en el primero de los elementos mencionados- no se exige en la figura de los abandonos transitorios.

Con todo, siendo cierto lo anterior, la redacción que utiliza el Código para configurar estas infracciones obliga a separar distintos estadios. Por una parte, no cabe duda que la mera circunstancia de incurrir en un retraso al comienzo de la jornada no se inserta dentro de la hipótesis del artículo 160 No 3 CT, ya que la impuntualidad se asocia más con el hecho de llegar tarde al inicio de la jornada. Distinto sería la situación derivada de abandonos transitorios o ausencias que se verifican antes de terminar la jornada de trabajo. Estas dos últimas alternativas se vinculan más con la hipótesis consagrada en la segunda parte del artículo $160 \mathrm{~N}^{\circ} 3 \mathrm{CT}$, que con figuras propias de impuntualidad. Por ello, a nuestro entender los supuestos de abandono momentáneo (y perjudicialmente grave) dentro de la jornada, así como el abandono del puesto de trabajo antes de concluir la misma, perfectamente pueden situarse dentro de la causal en comento ${ }^{17}$.

En otro orden de ideas, la figura del abandono que se regula en el artículo $160 \mathrm{~N}^{\circ} 3$ CT permite presumir la existencia de tres alternativas distintas. La primera de ellas es el abandono de puesto de trabajo; es decir, detraer el tiempo debido al desempeño de un determinado cargo o función así pactada en el contrato ${ }^{18}$. La segunda, es el abandono

${ }^{16}$ Cfr. por todas sentencia de la Corte Suprema de 11 de octubre de 1994, RDJ, T. XCI, sección tercera, 1994, p. 160.

${ }^{17}$ Criterios distintos pueden observarse en parte de la doctrina comparada. Por ejemplo, y entre otros, cfr. Arias, cit., pp. 38 y 39; y Pedrajas, A., y Sala, T., Ausencias al trabajo y absentismo, Tirant lo Blanch, Valencia, 2009, p. 17.

${ }^{18}$ Cfr. Gómez, F. J., La causalidad del despido disciplinario, Civitas/Thomson Reuters, Madrid, 2009, p. 125. 
de funciones, y dentro del cual habría que incorporar los supuestos en que el trabajador retarda o se niega la ejecución de una tarea específica, aun cuando pueda concurrir mera presencia física. La tercera, por último, se vincula con el abandono de destino, lo que comprende la ausencia física del sitio o recinto en el cual se ejerce el cargo, así como el incumplimiento absoluto de las obligaciones vinculadas al mismo. Si bien es cierto que algunas de estas alternativas también se encuentran recogidas en el artículo $160 \mathrm{~N}^{\circ} 4$ CT, nada impide concluir que dentro del núcleo de la infracción a que hace referencia el numeral tercero también se engloban estos distintos tópicos de abandono.

La paralización, por su parte, importa una situación de hecho que se grafica en la detención, o en un principio de detención, de la máquina, faena o actividad. En la paralización no se produce una simple dejación sino que se provocan consecuencias directas que en definitiva importan detener, entorpecer o impedir el ejercicio normal de las actividades de una organización. Dentro de la paralización quedarían, por ejemplo, la inmovilización de vehículos necesarios para el funcionamiento de la empresa, la detención de máquinas indispensables para la actividad de una sección de la misma, o el irregular funcionamiento de los instrumentos de la empresa ${ }^{19}$.

\subsection{El carácter con el cual la norma prefigura al sujeto infractor}

La redacción utilizada por la norma del artículo 160 N 3 CT parece no dejar demasiado espacio a la idea de que el autor de la infracción solo puede ser un trabajador que tiene un determinado nivel de responsabilidad sobre una actividad, máquina o faena. Dicha responsabilidad supone una suerte de deber de custodia que le exige un especial cuidado y celo sobre el funcionamiento regular de la actividad, máquina o faena. Por eso mismo, el tener a cargo estas figuras no implica necesariamente tenerlas de forma material; más bien, lo que se busca es que el destinatario de la norma sea un trabajador con un deber especial de cuidado y que tiene un nivel de responsabilidad relevante, de forma tal que su ausencia provoca los efectos que enumera el Código.

Consecuente con lo anterior, la causa disciplinaria se encamina en la práctica a prohibir las faltas o inasistencias de aquellos trabajadores especializados, con altos niveles de calificación para el desempeño de sus labores (de forma tal que resulta difícil de reemplazar), y precisamente por ello con niveles importantes de responsabilidad sobre la actividad, faena o máquina. Ese carácter de personal especializado o calificado permite concluir que la norma está pensada para aquellos trabajadores cuya presencia sea indispensable, tanto por la naturaleza de la actividad o máquina, como por el hecho de que la prestación de los demás trabajadores o el funcionamiento del ciclo productivo dependan en gran medida de dicho sujeto calificado ${ }^{20}$.

${ }^{19}$ Vid., en esta línea, Davis, cit., pp. 59 y 60, quien con apoyo jurisprudencial plantea la situación que se configura a partir del desobedecimiento o la burla de las órdenes impartidas por el superior por parte de los trabajadores, que se negaban a prestar servicios en sus labores ordinarias, por el simple procedimiento de no entrar al local en donde esos trabajos debían cumplirse.

${ }^{20}$ Cfr. Macchiavello, cit., T. I, cit., p. 520. 
A mayor abundamiento, la naturaleza de la función deja al descubierto que el trabajo desempeñado exige una prestación ininterrumpida y una asistencia regular al mismo. El potencial infractor tiene a su cargo la actividad, faena o máquina, y su abandono por tanto provoca una seria perturbación en la marcha de la empresa ${ }^{21}$. No hay que olvidar que en estos casos la causal vincula el abandono a la existencia de una perturbación grave en la marcha de la obra, y si existiera un reemplazante desde luego que lo más probable es que no se produciría la perturbación que se intenta evitar ${ }^{22}$.

Por otra parte, la circunstancia de que el trabajador tuviere a su cargo una actividad, faena o máquina, permite dejar de lado aquellos supuestos en que el trabajador simplemente se encontraba en una situación de hecho pero sin un deber jurídico de responsabilidad sobre la máquina o actividad en cuestión. Si bien es cierto el contrato de trabajo le impone al deudor laboral algunos actos destinados a evitar perturbaciones o perjuicios en la empresa, de igual modo habrá que aceptar que la hipótesis contenida en la segunda parte del artículo $160 \mathrm{~N}^{\circ} 3$ CT solo se encuentra centrada en un trabajador que tiene a su cargo una actividad, faena o máquina (como si fuese una especie de garante del normal funcionamiento de cada una de ellas).

Esta condición de responsable permitiría incluir dentro de la infracción, al menos teóricamente, los casos de omisión en que incurra el sujeto responsable o especializado (v. gr., un trabajador que tiene a su cargo una máquina y observa que un compañero de labores oculta las llaves de la misma sin realizar actos destinados a evitar las consecuencias del ocultamiento). No obstante, la redacción utilizada por el Código parece poner el énfasis en la realización de actos positivos y no tanto en supuestos de omisión (que por lo demás podría dar lugar a otro tipo causales vinculadas al incumplimiento grave de las obligaciones).

\subsection{El objeto del abandono o paralización: la actividad, faena o máquina}

Como se ha dicho, la segunda parte del artículo $160 \mathrm{~N}^{\circ} 3$ CT intenta resguardar el normal funcionamiento de la máquina, de la actividad o de la faena. Al igual que en

${ }^{21}$ La doctrina nacional (cfr. Lizama, L., Derecho del Trabajo, LexisNexis, Santiago, 2003, p. 177) ha colocado como ejemplos de este tipo de trabajadores a los capataces, supervisores, jefes de obra, o controladores de aeropuerto (en el caso de una actividad o faena); y a los conductores de vehículos especiales e imprescindibles para el desarrollo de una actividad (en el supuesto de las máquinas). También, la doctrina correspondiente a la Ley $\mathrm{N}^{\circ} 16.455$ (vid. Davis, cit., p. 58) puso como ejemplo de infractor de esta causal a los operadores de palas y dragas electromecánicas, los torneros, fresadores y matriceros, los mecánicos, electricistas, los maquinistas de locomotoras de arrastre, o los pilotos de avión, entre otras alternativas. Criterios similares se pueden observar en el derecho comparado, cuando se hace referencia al despido de un "encargado o supervisor que se retira sin autorización y deja sin control al personal a su cargo"; o "el abandono del lugar de trabajo de la empleada que atendía una unidad coronaria, con pacientes internados" (vid. Vázquez, A., Tratado de Derecho del Trabajo, T. 5, Astrea, Buenos Aires, 1993, p. 387, nota 896). La misma lógica se sigue en el despido de un trabajador que ocupa puestos de relevancia en el ámbito marítimo o aéreo, "debido a las condiciones de riesgo y peligro en que ha de desarrollarse este tipo de trabajo” (vid. García-Núñez, F., "La indisciplina o desobediencia en el trabajo como causa del despido disciplinario (art. 54.2 b ET)”, AL N 2 [2005], p. 1828).

${ }^{22}$ Cfr. Davis, cit., p. 58. 
otras causas establecidas en el artículo 160 CT, la referencia a la actividad, faena o máquina tiene una vocación más bien generalista así como una clara intención referencial. Cuando el Código menciona a la máquina, en el fondo está poniendo el acento en aquel conjunto de bienes materiales que (sin ser necesariamente esenciales) son relevantes para colocar en funcionamiento una actividad dentro de la empresa. No se trata, por tanto, de cualquier bien sino de uno que tenga un carácter relevante desde el punto de vista del funcionamiento general de la obra. A mayor abundamiento, la expresión máquinas se relaciona con los artefactos o utensilios necesarios tanto para un fin determinado como para el conjunto de piezas que componen un mecanismo y que sirven para poner en funcionamiento un aparato o un bien relevante de la empresa.

La actividad, por su parte, se vincula al conjunto de funciones, operaciones y tareas propias del giro de la empresa o de alguno de sus establecimientos. Si la actividad de la empresa se ve perturbada, entonces esta pierde eficacia para el cumplimiento de sus fines propios. La faena, por último, nos reconduce a la figura de una obra o trabajo material o intelectual determinable. Si bien es cierto que la legislación chilena no ha definido expresamente el alcance del vocablo faena (aun cuando reconoce su existencia en distintas normas del Código), de todas formas su invocación tiene una clara relación con obras o tareas específicas y determinadas ${ }^{23}$.

${ }^{23}$ En el Derecho chileno, las referencias a la faena vienen desde las primeras leyes sociales. En efecto, el artículo $2^{\circ}$ del antiguo Código del Trabajo de 1931, al definir al "patrón o empleador" ya configuraba como sinónimos las figuras de la empresa o faena "de cualquier naturaleza o importancia, en que trabajen obreros o empleados, cualquiera que sea su número”. Si bien esta definición perduró hasta la publicación del Decreto Ley $\mathrm{N}^{\circ} 2.200$, de 1978, lo cierto es que la conceptualización antedicha fue objeto de diversas críticas por parte de la doctrina (cfr. Irureta, P., "La noción jurídica de empleador ante el Derecho del Trabajo, RD XLII, segundo semestre [2014], pp. 251 y ss). En la actualidad, una definición indirecta de faena puede encontrarse en el Decreto Supremo $N^{\circ} 76$, de 2006, que aprobó el Reglamento para la aplicación del artículo 66 bis de la Ley $\mathrm{N}^{\circ} 16.744$ sobre la gestión de la seguridad y salud en el trabajo en obras, faenas o servicios. Según el artículo mencionado, se entiende por obra, faena o servicios, "todo proyecto, trabajo o actividad destinado a que la empresa principal desarrolle sus operaciones o negocios, cuya ejecución se realice bajo su responsabilidad, en un área o lugar determinada, edificada o no, con trabajadores sujetos a régimen de subcontratación". Asimismo, en el Código del Trabajo existen múltiples referencias al vocablo faena. Aunque sin definirla, el Código tiende a establecer este término como sinónimo de empresa o establecimiento, o bien de actividad. Cuenta de ello dan los artículos 14 (sobre trabajo de menores); 23 (sobre descanso en naves pesqueras); 29 (sobre extensión de la jornada ordinaria en supuestos de caso fortuito o fuerza mayor); 31 (sobre horas extraordinarias); 35 bis (sobre interferiados); 37 (sobre empresas o faenas no exceptuadas del descanso dominical); $38 \mathrm{~N}^{\circ} 1$ (sobre trabajadores exceptuados del descanso dominical); $38 \mathrm{~N}^{\circ} 6$ (sobre faenas portuarias); 38 inciso final (sobre autorización de jornada excepcional), 66 bis (sobre permiso para realización de exámenes); 87 (sobre faenas agrícolas); 92 bis inciso (sobre intermediación agrícola); 93,94 y 95 (sobre trabajadores agrícolas); 133, 134, 137 y 140 (sobre trabajadores portuarios eventuales); 153 y 154 (sobre Reglamento Interno); 183-A, 183-D, 183-E (sobre subcontratación); 183-Ñ (sobre contrato de puesta a disposición); 184, 186, 187, 188, 189, 190 (sobre deber de higiene y seguridad); 209 (sobre seguro social contra riesgos de accidentes del trabajo y enfermedades profesionales); 211-G (sobre protección de los trabajadores de carga y descarga de manipulación manual); 243 (sobre fuero sindical); 247 (sobre actividades sindicales); 289 (sobre prácticas desleales); $305 \mathrm{~N}^{\circ} 1$ (sobre trabajadores impedidos de negociar colectivamente); 314 (sobre sindicato de trabajadores transitorios o eventuales); 355 (en caso de arbitraje obligatorio); y 385 (sobre decreto de reanudación de faenas). 


\subsection{Los efectos de la infracción: perturbación grave en la marcha de la obra}

La causal disciplinaria a que se hace referencia, requiere un resultado: la perturbación grave. Aquí no basta, por tanto, el mero abandono o paralización, y tampoco basta por sí sola la concurrencia de un determinado estado perturbador toda vez que la ley exige que sea cualitativamente relevante; es decir, que este sea grave. Lo anterior obliga a concluir que la hipótesis contenida en la segunda parte del artículo $160 \mathrm{~N}^{\circ} 3 \mathrm{CT}$ no constituye una infracción de peligro (ni abstracto ni concreto); y ello por la sencilla razón de que el Código exige la concurrencia de un resultado. Esta misma lógica obliga a dejar fuera del núcleo central de la causal las simples amenazas de perturbación o las infracciones de mera actividad (faltar), toda vez que la norma exige la producción de un efecto separado espacial y temporalmente de la conducta.

La perturbación implica una alteración o trastorno del orden habitual de la empresa o de una parte de ella. Se trata de un concepto objetivo, claramente identificable desde el punto de vista de la actividad de la empresa, y que ciertamente no puede confundirse con la mera percepción sicológica que el empleador tenga de un determinado hecho ${ }^{24}$. Desde esta perspectiva, la perturbación depende esencialmente de un resultado medible; y si ese resultado medible no existe, o es escaso, entonces la causal no resultaría aplicable.

La perturbación, por otra parte, no supone necesariamente perjuicio, o una disminución real y efectiva del patrimonio del empleador. Si así fuese, habrían dos tipos de causales aplicables a hechos perjudiciales toda vez que el artículo 160 No 6 CT exige precisamente el resultado de perjuicio. En el caso del artículo $160 \mathrm{~N}^{\circ} 3$ CT la figura es distinta, ya que la norma legal exige simplemente una afectación del orden regular de funcionamiento que existe en la actividad productiva. Y dicho orden regular se aplica a distintas facetas del proceso de producción. De allí que la jurisprudencia haya hecho extensiva la idea de perturbación a supuestos tales como el incumplimiento de algún contrato con un tercero o a las dificultades para proceder al despacho oportuno de transporte de mercaderías o productos ${ }^{25}$.

Con todo, y como es ampliamente sabido, no se trata de cualquier perturbación. El Código exige que la misma sea grave; y ello nuevamente nos reconduce a la idea de que la infracción debe ser de una entidad suficiente en que la medida sancionadora naturalmente aplicable es la extinción del vínculo ${ }^{26}$. Desde esta perspectiva, la gravedad

${ }^{24}$ Cfr. sentencia de la Corte de Apelaciones de Rancagua de 19 de febrero de 1986, RDJ T. LXXXVIII, sección tercera, 1986, p. 29.

${ }^{25}$ Cfr. sentencia del Primer Juzgado del Trabajo de Antofagasta (Rol Tribunal 1962-93), en RDJ T. XCII, sección tercera, 1995, pp. 95 y ss.

${ }^{26}$ Vid. en esta línea sentencia de la Corte de Apelaciones de Rancagua de 19 de febrero de 1986, RDJ T. LXXXIII, sección tercera, 1986, p. 29. En dicho fallo, la Corte concluyó que la simple intranquilidad o preocupación que habrían tenido los ocupantes de unos locales comerciales por la ausencia al trabajo de los vigilantes privados, "no puede ser estimada como una perturbación grave en la marcha de dichos negocios", más aún si "el trabajo de los inasistentes fue desempeñado por otros vigilantes”. 
debe ser evaluada de acuerdo con la teoría gradualista, analizando las circunstancias del caso así como los efectos producidos por la conducta del trabajador ${ }^{27}$.

Por último, y en una clara utilización del lenguaje propio de las primeras leyes sociales, el Código exige que la perturbación afecte la marcha de la obra. Se trata de un típico concepto de base patrimonial y de clara evocación a la manualidad del trabajo. En el contexto de las primeras leyes sociales, la expresión adquiría pleno sentido más aún si tenía por objeto regular el contrato de $\operatorname{los}_{\text {obreros }}{ }^{28}$. En la actualidad, no obstante, la expresión debe ser vista como una referencia más vinculada al funcionamiento del centro de trabajo, de modo tal que en dicho ámbito se produce la concreción específica del ejercicio de las relaciones laborales. En otras palabras, la obra termina reconduciendo a la unidad básica en la cual los sujetos que se hayan vinculados laboralmente terminan relacionándose no tanto en el ámbito de una empresa, en sentido abstracto, sino con la unidad productiva en la que se prestan los servicios; ya que es allí, en definitiva, donde se plasmará el mayor número de relaciones individuales y colectivas de trabajo. Dicho en otros términos, en la hipótesis del artículo 160 No 3 CT el vocablo obra parece relacionarse más bien con las ideas de establecimiento, explotación, industria o negocio, aun cuando habrá que reconocer que no existe una idea jurídica unitaria de la obra ${ }^{29}$.

\section{CONCLUSIONES}

1. La figura extintiva consagrada en la segunda parte del artículo $160 \mathrm{~N}^{\circ} 3 \mathrm{CT}$, busca asegurar el cumplimiento cabal y diligente del contrato de trabajo así como evitar perjuicios patrimoniales al empleador. Si bien se trata de una peculiar figura de abandono, lo cierto es que esta causal se entrelaza con otros supuestos de inasistencia que consagra la misma norma antes mencionada.

\footnotetext{
${ }^{27}$ Cfr. por todos Alonso, M., El despido, Instituto de Estudios Políticos, Madrid, 1958, p. 147.

${ }^{28}$ Las referencias lingüísticas en orden a que la organización empresarial deba ser vinculada con una obra son propias de aquellas tesis que ven a la empresa como un objeto de derecho, dando lugar a la realización de un acto jurídico sobre ella. Esta concepción de la empresa permite observar a sus componentes como cosas en sentido jurídico, bienes materiales y, eventualmente, bienes inmateriales de valor económico, derecho de la personalidad, relaciones jurídicas crediticias activas y pasivas, relaciones fácticas, o el valor de la organización unitaria que se trata de captar (cfr. Girón, J., Apuntes de derecho mercantil. La empresa. T. I, Facultad de Derecho Universidad Complutense, Madrid, 1985-1986, p. 8. En el plano jurisprudencial vid., sentencia de la Corte Suprema de 28 de diciembre de 1971 [considerando $8^{\circ}$ ], RDJ T. LXVIII, sección primera, 1971, p. 395. En igual sentido, vid., también, sentencia de la Corte Suprema de 31 de agosto de 1953, RDJ T. 1, sección primera, 1953, p. 341; y sentencia de la Corte Suprema de 17 de agosto de 1953, RDJ T. 1, sección primera, 1953, p. 292). Esta visión objetiva ha encontrado especial resonancia en aquellas normas que regulan los eventuales cambios de titularidad empleadora (tal como ocurre en el artículo $4^{\circ} \mathrm{CT}$ ).

${ }^{29}$ En el ámbito doctrinario, cfr. Monereo, J. L., Las relaciones de trabajo en la transmisión de la empresa, Centro de Publicaciones Ministerio de Trabajo y Seguridad Social, Madrid, 1987, p. 220. Vid. también González, E., El cambio de titularidad de la empresa en el Derecho del Trabajo, Centro de Publicaciones Ministerio de Trabajo y Seguridad Social, Madrid, 1987, pp. 83 y ss.
} 
2. El destinatario de la hipótesis extintiva es fundamentalmente un trabajador con niveles relevantes de responsabilidad o capacidad técnica. Hacia él va dirigida la causal, pues el Código entiende que su falta o inasistencia no permite que sea reemplazado por el empleador.

3. La causal contenida en la segunda parte del artículo $160 \mathrm{~N}^{\circ} 3 \mathrm{CT}$ se centra en las faltas relevantes y transitorias. Cuando se habla de transitorias se está vinculando el concepto a supuestos de inasistencia inferiores a dos días (o dos lunes en el mes o tres días en el mismo período), cuestión que obliga a calificar judicialmente el elemento temporal desde un punto de vista cuantitativo.

4. El abandono que para efectos de esta causal reprocha el Código se relaciona con alternativas tan disímiles como el abandono de puesto de trabajo, el abandono de funciones y el abandono de destino, conceptos todos que están íntimamente vinculados con la idea de actividad del trabajador. La paralización, por su parte, se relaciona más estrechamente con la detención de la máquina o la faena.

5. La falta injustificada o sin aviso previo requiere, para fundamentar el despido, la concurrencia de una perturbación grave en la marcha de la obra. Ello deja en evidencia que para el legislador no basta el mero abandono o paralización; así como tampoco un simple estado perturbador. Por el contrario, la ley exige un determinado resultado, de entidad relevante, cuestión que obliga a dejar fuera del núcleo definitorio de la causal las simples amenazas de perturbación o las infracciones de mera actividad.

\section{BiBLIOgRAFÍA}

Alonso, M., El despido, Instituto de Estudios Políticos, Madrid, 1958.

Altes, J.A., Blasco, Á., y Nores, L.E., El despido objetivo, Tirant lo Blanch, Valencia, 2010.

Arias, Á., Absentismo laboral. Civitas/Thomson Reuters, primera edición, Madrid, 2013.

Davis, P.R., Terminación del contrato de trabajo, Editorial Bibliográfica Chilena, Santiago, s/f.

De Buen, N., Derecho del Trabajo, T. II, Porrúa, $9^{a}$ edición, México, 1992.

Domínguez, M., Manual para la aplicación de la Ley $N^{o} 16.455$ y su reglamento sobre inamovilidad en el empleo, Edilex, Santiago, s/f.

García-NúÑeZ, F., "La indisciplina o desobediencia en el trabajo como causa del despido disciplinario (art. 54.2 b ET)", AL N 2, 2005.

GIL, J., "Las faltas repetidas e injustificadas de asistencia o puntualidad al trabajo como causa de extinción de los contratos", AL N ${ }^{\circ}$ 1, 2005.

Girón, J., Apuntes de Derecho Mercantil. La Empresa, T. I, Facultad de Derecho Universidad Complutense, Madrid, 1985-1986.

GonZÁlez, E., El cambio de titularidad de la empresa en el Derecho del Trabajo, Centro de Publicaciones Ministerio de Trabajo y Seguridad Social, Madrid, 1987.

IruReta, P., "La noción jurídica de empleador ante el Derecho del Trabajo", RD XLII, segundo semestre, 2014.

Lizama, L., Derecho del Trabajo, LexisNexis, Santiago, 2003.

Macchiavello, G., Derecho del Trabajo T. I, Fondo de Cultura Económica, Santiago, 1986.

Monereo, J.L., Las relaciones de trabajo en la transmisión de la empresa, Centro de Publicaciones Ministerio de Trabajo y Seguridad Social, Madrid, 1987. 
Montoya, A., Derecho del Trabajo, Tecnos, 29a edición, Madrid, 2008.

Pedrajas, A., y Sala, T., Ausencias al trabajo y absentismo, Tirant lo Blanch, Valencia, 2009.

Rodríguez, E., "Las faltas de asistencia o puntualidad al trabajo como infracción disciplinaria: su regulación convencional", AFDO N 1, 2006.

Sagardoy, J.A., El despido laboral y los expedientes de crisis, Ediciones Deusto, Bilbao, 1969.

VÁzquez, A., Tratado de Derecho del Trabajo, T. 5, Astrea, Buenos Aires, 1993. 